\title{
Geophysical Signatures of some recently discovered Angolan Kimberlites
}

\author{
Wayne Pettit \\ BHP Billiton World Exploration Inc., 6 Hollard Street, Marshalltown, Johannesburg, 2001, South Africa.
}

\section{Introduction}

In 2004 BHP Billiton entered into a joint venture with Petra Diamonds in partnership with Endiama and Moyoweno (Davidson, 2006). BHP Billiton agreed to fund and operate the kimberlite exploration program on the Alto Cuilo concession in the northeast of Angola. The work program included geophysically guided exploratory, delineation and bulk sample drilling.

\section{Geological setting}

At Alto Cuilo the magnetic Archean basement is estimated to lie between $350 \mathrm{~m}$ to $650 \mathrm{~m}$ below surface. It is overlain by magnetically transparent Karoo shale and sandstone beds. No Karoo age basalt or dolerite is present on the property. This provides an ideal setting to detect even weakly magnetic bodies.

Cretaceous age kimberlites intrude through the Karoo sediments into unconsolidated aeolian Calonda Formation sands, where the craters are well preserved and tend to flare. They are covered and partly filled by the Calonda units, which are overlain by Kalahari Group formations and recent sand. The average cover thickness in the area of focus is approximately $45 \mathrm{~m}$.

In a few locations crater facies sand and resedimented volcaniclastic kimberlite (RVK) have been exposed by erosion. However, most of the kimberlites are located under cover in the interfluves between drainages. Drill testing of these targets is of necessity guided primarily by the interpretation of their geophysical signatures.

\section{Airborne geophysical signatures}

A fixed wing magnetic survey was conducted in 1997 on 200m spaced lines with a nominal sensor height of $75 \mathrm{~m}$. To follow up the fixed wing anomalies a lowlevel helicopter borne magnetic gradiometer survey was conducted in place of ground magnetic surveys. The mean sensor height was $20 \mathrm{~m}$ above hazard, and the line spacing was $100 \mathrm{~m}$.

Large kimberlite bodies identified in the fixed wing survey are brought sharply into focus in the helicopter data (Pettit, 2006). In addition, several textural features with diameters in the order of $1000 \mathrm{~m}$ are revealed. An example is shown in Figure 1, where the AC70 kimberlite is evident as a subtle texture $(<1 \mathrm{nT})$ in the magnetic image. These magnetic signatures would be thoroughly masked in a busy magnetic environment.

In this setting exploratory drilling on magnetic features has been extremely successful at discovering new kimberlites. The important subsequent task was to identify which kimberlites amongst the many most warranted further delineation work. This required at least one targeted narrow diameter diamond (NDD) borehole to be drilled into each pipe for the purpose of Heavy Mineral Analysis (HMA) and microdiamond (MiDa) sampling. Favorable kimberlite pipes were then scheduled for large diameter drilling in order to collect a mini bulk sample (MBS).

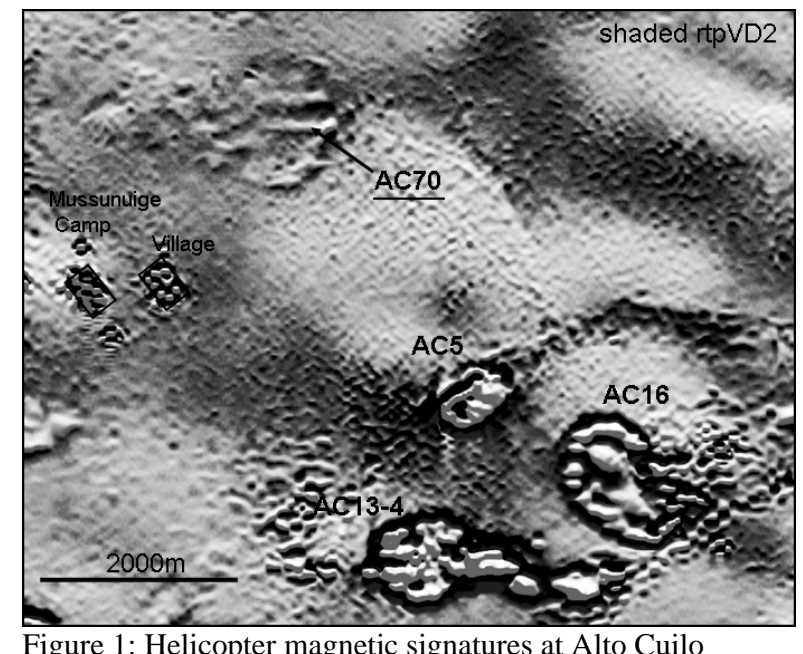

\section{Ground geophysical signatures}

The gravity and magnetotelluric methods were deployed on the selected kimberlite pipes to guide delineation and MBS drilling. Line spacing was either $100 \mathrm{~m}$ or $200 \mathrm{~m}$ depending on the size of the target, and stations were spaced $50 \mathrm{~m}$ apart.

Gravity data were collected using a low drift Scintrex CG3 gravimeter and a precision Leica DGPS system. Accurate terrain data are essential to reduce the noise in the corrected Bouguer anomaly. A reduction density of $2.0 \mathrm{~g} / \mathrm{cc}$ was used to minimize correlations between topography and the gravity anomaly.

The natural source audio magnetotelluric (NSAMT) method was selected for it's ability to investigate to the desired depth (up to 500m) and because it does not require transmitter loops and generators. The array used was a $100 \mathrm{~m}$ in-line spread with two 50m Ex dipoles, two 50m Ey dipoles and centrally placed orthogonal $\mathrm{Hx}$ and Hy sensors. Zonge ANT6 coils were used for the $\mathrm{H}$-field sensors and brass stakes for the current dipole electrodes. A Zonge GDP32 receiver was used to record the tensor far-field readings at 30 frequencies in the range $3 \mathrm{~Hz}$ to $8 \mathrm{kHz}$. Reading times were 20-25 minutes at each station. 
Specific gravity (SG) measurements were made on representative core samples taken every $3 \mathrm{~m}$ (about 10$20 \mathrm{~cm}$ of core). The determination method is weight in air vs. weight in water. Table 1 provides a summary of average in-situ densities for the predominant formations. The results do not predict a measurable contrast between the kimberlite and the Karoo host lithologies. However in deeper craters unconsolidated crater facies material is juxtaposed against Karoo sediments. In these situations subtle to significant gravity low anomalies may be obtained over the crater. In addition, fresh hypabyssal kimberlite may support a local gravity high in shallower cases.

\begin{tabular}{|c|c|c|c|c|c|c|c|c|}
\hline \multicolumn{9}{|c|}{ AVERAGE IN-SITU WET BULK DENSITY $\mathrm{g} / \mathrm{cc}$ (no. of samples) } \\
\hline BHID & SDST & RVK & VK & TK & HK & CRB & KAROO & Karoo_fm \\
\hline \begin{tabular}{|l|l}
$A C 09-03$ \\
\end{tabular} & & & & & & & 2.23 (6) & shale \\
\hline ACO9-04 & & $2.33(12)$ & & 2.16 (5) & & $2.44(4)$ & & \\
\hline ACO9-05 & $2.11(17)$ & $2.16(23)$ & & & & & & \\
\hline Ac42-01 & & $2.15(20)$ & & & & & & \\
\hline AC42-05 & & & & $2.35(7)$ & 2.63 (b) & & $2.51(10)$ & sst/shale \\
\hline AC42-08 & & & & & & & $2.28(20)$ & lam shale \\
\hline \begin{tabular}{|l|}
$A C 42-10$ \\
\end{tabular} & $2.00(30)$ & & & & & & & \\
\hline AC60-10 & $2.03(26)$ & $2.25(13)$ & $2.36(7)$ & & & $2.27(24)$ & $2.32(11)$ & shale \\
\hline AC63-03 & $2.08(30)$ & $2.33(4)$ & & & & $2.38(3)$ & $2.04(5)$ & sst \\
\hline AC60-07 & $2.06(38)$ & $2.34(12)$ & & & & $2.40(12)$ & $2.46(6)$ & sst/shale \\
\hline AC71-08 & $2.07(38)$ & $2.31(3)$ & $2.53(4)$ & & & & $2.52(4)$ & shale \\
\hline AC98-02 & $2.26(23)$ & $2.21(20)$ & & & & & & \\
\hline AC98-05 & 2.03 (8) & $2.16(48)$ & & & & $2.21(7)$ & & \\
\hline AC98-08 & $2.17(15)$ & & & $2.12(3)$ & & & & \\
\hline AVERAGE & 2.0 & 2.25 & 2. & 2.21 & 2.63 & 2.34 & 2.34 & \\
\hline
\end{tabular}

Table 1: In situ densities of the main formations at Alto Cuilo

Petrographic studies reveal that kimberlite magnetism is sourced in microscopic primary magnetite. Routine magnetic susceptibility (MSUS) measurements were made at $1 \mathrm{~m}$ intervals on all cores using a hand held magnetic susceptibility meter. Susceptibility is a useful indicator of kimberlite facies, as indicated in Figure 2. In the pipes of interest massive RVK typically has MSUS values from $2-4 \times 10^{-3}$ SI. Sand dilution may reduce this by an order of magnitude to an average of $0.4 \times 10^{-3}$ SI. The deeper VK units typically have consistent MSUS values of $1-1.5 \times 10^{-3}$ SI. The implication is that accumulations of shallow, massive RVK in or around the craters will dominate the magnetic signature.

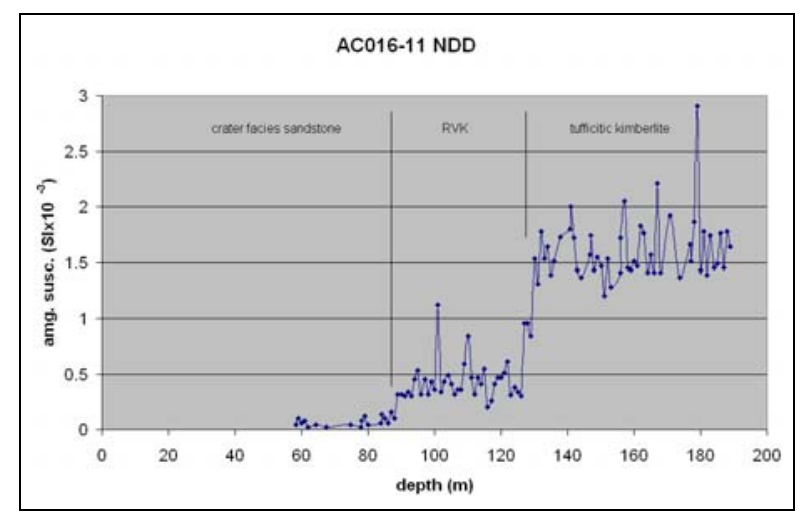

Figure 2: Magnetic susceptibility log on borehole core

No formation resistivities were measured. However, consistent inversion model results recover resistivity values of around 1-3ohm.m for weathered, reworked kimberlite, and 100-400ohm.m for the Kalahari cover. Recovered resistivites for the Karoo shales and sandstones range between 1 and 20ohm.m, which means that the resistivity contrast between Karoo host and kimberlite is small to negligible.

The expected geophysical signatures are illustrated in several of the large kimberlites that were investigated in the MBS program at Alto Cuilo. Kimberlite AC42 illustrates the case of a large crater filled with crater facies sandstone (SDST) and RVK producing a strong gravity low anomaly that indicates the position of the vent. See Figure 3. The crater is also well delineated by the helicopter magnetic data. The magnetic anomaly is enhanced in the south where erosion has left the massive RVK units nearer to the surface.

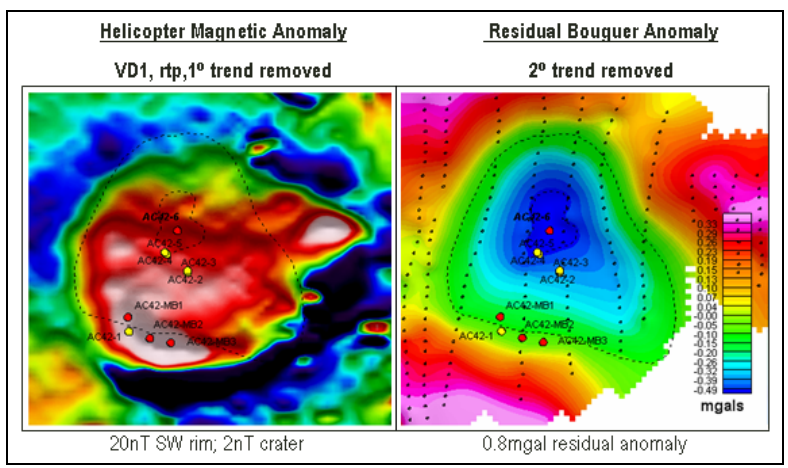

Figure 3: Magnetic and gravity signature of kimberlite AC42

In remarkable contrast, pipe AC70 has a similar diameter and depth but it has no appreciable gravity signature. Neither does the magnetic signature shown in Figure 4 provide any obvious drilling targets. In this case NSAMT data have more clearly imaged the large, RVK and sand filled crater, as shown in Figure 5.

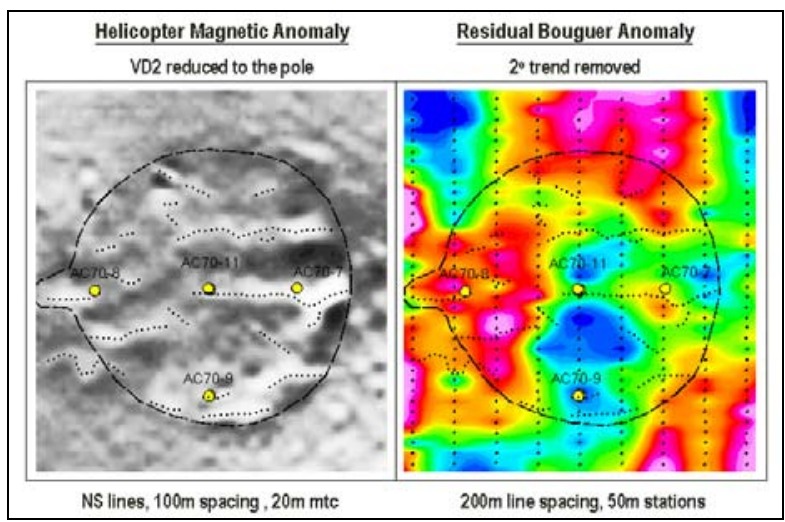

Figure 4: Magnetic and gravity signature of kimberlite AC70

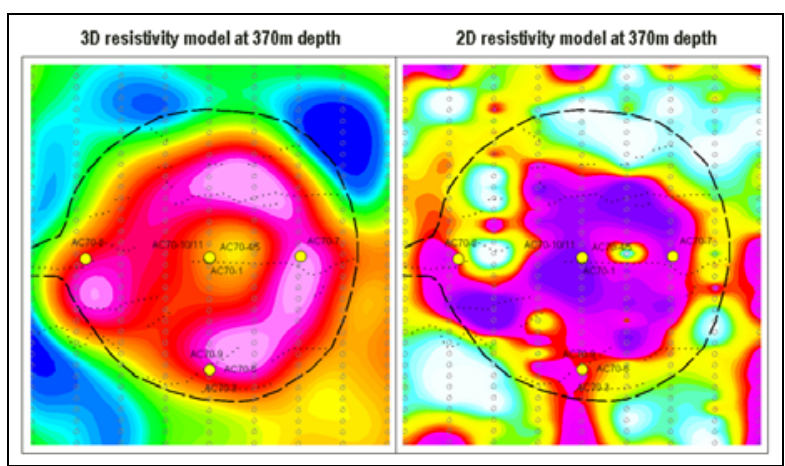

Figure 5: Resistivity signature of kimberlite AC70; 370m depth slices from 3D and 2D inversion of NSAMT data 
The NSAMT data were modeled using a 2D smooth inversion algorithm weighted to a 1D starting model. The resulting models accurately map the contact between the cover sequence and the Karoo host lithologies. They also indicate a transition with depth from shale to sandstone. Features related to the kimberlites tend to be poorly formed in the 2D models due to the $3 \mathrm{D}$ nature of the pipe. A proprietary full domain 3D MT inversion routine is under development utilizing all frequencies in both TM and TE modes.

An initial unconstrained 3D inversion model of the AC70 pipe provides a much improved image of the kimberlite features and possibly resolves the top of the resistive basement. Beneath $40-80 \mathrm{~m}$ of cover the crater is filled with bedded and unconsolidated sands to a maximum depth of almost 400m near the center of the crater. The MSUS data indicate the presence of an RVK unit between 75 and $90 \mathrm{~m}$. Both this unit and the true depth of the sand fill are more accurately mapped in the 3D NSAMT models.

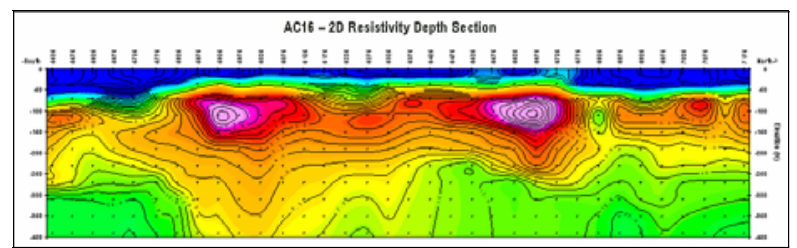

Figure 6: Weighted 2D inversion resistivity section for kimberlite AC16

An example of the 2D NSAMT model sections is given in Figure 6 for pipe AC16. Up to 20m of paleo-relief is indicated over the crater. The thinning of the Kalahari over this feature probably accounts for a unique gravity high signature identified over this pipe. Residual gravity highs are thought to indicate local paleo relief. Where they coincide with positive magnetic anomalies thicker massive RVK units may be indicated.

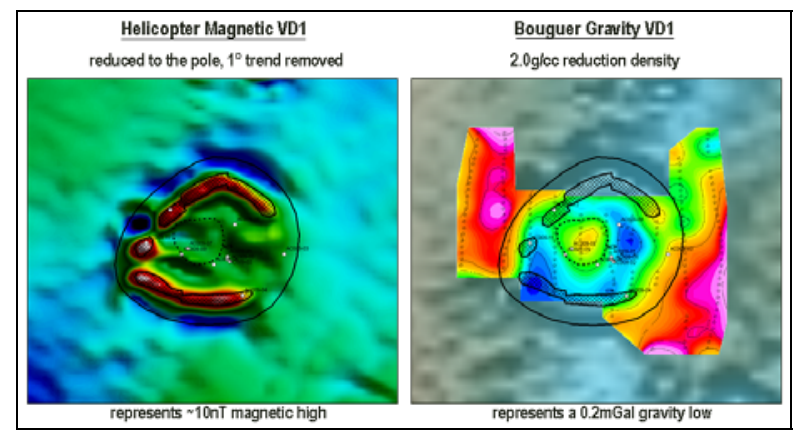

Figure 7: Geophysical signature of kimberlite AC09

Kimberlite AC09 is located in the flood plain of a river that has stripped the cover. This pipe is buried at depths of only $4-20 \mathrm{~m}$. The details in the magnetic data shown in Figure 7 clearly mark the location of shallow, massive RVK beds around the rim of the crater. The diluted, bedded RVK facies gives rise to a general subtle magnetic high over the crater. There is an unusual weak central gravity high anomaly in this crater that has not been explained by drilling to date.

\section{Conclusions}

At Alto Cuilo the only source of magnetism on the project is primary or detrital magnetite sourced in kimberlite. Airborne magnetic surveys have identified numerous new, weakly magnetic, covered kimberlite pipes. Low level helicopter magnetic data provide subtle detail on kimberlite facies distribution. In these pipes the significant magnetic anomalies appear to arise from shallower and/or thicker intervals of massive RVK typically located around the crater rims.

MT data corroborate this conclusion. NSAMT surveys have successfully mapped extremely small resistivity contrasts between the kimberlite and the host rock to depths of well over $400 \mathrm{~m}$ in a relatively conductive terrain. More conductive zones appear to correspond to massive weathered RVK beds in or around the perimeter of the craters. Full domain $3 \mathrm{D}$ inversion greatly improves the geometric form and depth accuracy of the resistivity models.

Residual Bouguer gravity lows of between 0.2 and $0.8 \mathrm{mgals}$ have successfully indicated vent locations beneath preserved craters under as much as $50 \mathrm{~m}$ of cover and in some instances delineate craters that are larger than the size indicated by magnetic anomalies.

Combined with geochemical and mineralogical prioritization techniques, geophysical signatures in magnetic, gravity and electromagnetic data have provided a sound basis to guide exploratory, delineation and mini bulk sample drilling of a little known kimberlite cluster buried beneath cover in Angola's premium kimberlite province.

The variation in geophysical signatures underscores the importance of combining all three independent geophysical methods to efficiently achieve kimberlite exploration and evaluation goals in any given geological setting, a result similar to that expressed previously by another author (Hatch, 2001).

\section{References}

Davidson, J., 2006. A brief history of the Alto Cuilo kimberlite discoveries, Angola. A presentation to the Geological Society of South Africa at the Kimberlite Symposium in Johannesburg, September 2006.

Hatch, D., 2001. Finding the difficult ones: Diamond exploration in Africa. A presentation to the South African Geophysical Association in Johannesburg, October 2001.

Pettit, W., 2006. The magnetic illumination of kimberlites at Alto Cuilo, Angola. A presentation to the Geological Society of South Africa at the Kimberlite Symposium in Johannesburg, September 2006. 